\title{
PROBLEMAS TEOLÓGICOS MUSULMANES Y CRISTIANOS EN EL ENFRENTAMIENTO DE LOS ÚLTIMOS MUSULMANES DE ESPAÑA CON LOS PODERES CRISTIANOS
}

Por

MÍKEL DE EPALZA

En este texto, forzosamente condensado, se quisiera proponer una problemática a dos niveles, que permitiera conocer mejor el poder que representaba la Inquisición, junto a la Iglesia y el Estado cristianos, y conocer también el desarrollo del enfrentamiento islamo-cristiano en España a través de la evolución tardomedieval y moderna del problema de los musulmanes insertados en la sociedad cristiana. Hay un nivel constante, el de la defensa musulmana ante el poder cristiano. $Y$ hay un nivel con variaciones temporales, que es el de los acosos cristianos sucesivos y sus correspondientes respuestas musulmanas. Se verá esta evolución a partir de los problemas religiosos que se plantean a las dos comunidades.

\section{La evolución de los problemas teológicos musulmanes}

El Islam es más que una espiritualidad. Sitúa al creyente en el universo, en todas sus dimensiones. Le da una estructura mental y vital seguras, con tal de que colabore con las normas que Dios y su Revelación (el Corán, con la enseñanza del Profeta) le han revelado, para su seguridad en la salvación, en este mundo y en el otro. Estas normas religiosas abarcan también su actitud política, sobre todo en las adversidades semejantes a las que tuvieron que padecer el Profeta y sus Compañeros, al principio de Islam.

Hay que empezar por recordar que los musulmanes de al-Andalus tenían ya una experiencia colectiva de opresiones políticas, por sus propias autoridades musulmanas, a lo largo de toda la historia islámica de la Península. Por tanto, no es la opresión política de los cristianos (fiscal, administrativa, despótica, etc.) lo que les planteaba problemas especiales. Los problemas más graves provenían del carácter religioso 
de esta opresión, especialmente en época morisca (finales del siglo XV, hasta la expulsión de principios del XVII).

La primera tensión que se les planteaba era consecuencia de la conquista cristiana de los territorios musulmanes. Pasaban a depender de autoridades no-cristianas, lo cual es contrario al estatuto normal de la sociedad musulmana, tal y como lo define el Corán. Para que el Islam pueda ser la norma que da seguridad al creyente, estos creyentes tienen que vivir en una sociedad política con autoridades musulmanas que hagan cumplir la ley islámica. La sociedad en su conjunto tiene que regirse por esa ley, que prevé por otra parte un estatuto especial para judíos y cristianos, libres de practicar su religión, de conservar su cultura y de tener autoridades propias, con tal de que reconozcan la autoridad eminencial del gobierno islámico y paguen impuestos especiales.

El depender de autoridades no musulmanas es pues una situación jurídica y religiosa anormal, aunque está prevista por la legislación musulmana, especialmente en el caso de los viajeros y comerciantes en territorios lejanos. También es anómalo el que el Islam, míticamente triunfador y conquistador, con la ayuda divina, pierda territorios en al-Andalus.

Frente a esta situación, que es un mal previsto por el Corán, los musulmanes de al-Andalus, en los siglos XII y XIII, se adaptarán con batallas, negociaciones, revueltas mudéjares, despoblamiento de tierras atacadas, etc. No conseguirán restablecer la situación islámica precedente: mantener los territorios musulmanes bajo autoridades musulmanas.

Al quedar en territorios y bajo autoridades cristianas, en situación de mudéjares, los musulmanes de al-Andalus tiene la opción de marcharse a tierras musulmanas, como se lo mandan los preceptos islámicos (estudiados por Leila Sabbag), como lo vieron hacer a las clases dirigentes andalusies y como se lo aconsejan las múltiples dificultades que encuentran para vivir bajo autoridades cristianas arbitrarias y para vivir como musulmanes.

Pero los que se quedan se adaptarán a la nueva situación provocada por el poder estatal cristiano, manteniendo íntegro el sistema de seguridad musulmán, conservando la esperanza de una futura victoria militar con la ayuda de los otros poderes musulmanes (Granada, el Mágreb, los turcos...) y, sobre todo, sustituyendo la autoridad politica musulmana precedente - ella misma multiforme - por la de las aljamas, institución andalusí original en el Occidente musulmán y aún no suficientemente estudiada. Así, también en la situación mudéjar, los musulmanes de al-Andalus supieron mantener su sistema de securización religiosa íntegro y encontraron en el Islam la fuerza y los medios para defenderlo del reto que suponía el vivir en una sociedad política cristiana.

Si las conquistas territoriales cristianas, hasta la toma de Granada en 1492, produjo gran impacto en los musulmanes, más fuerte les pareció la pretensión cristiana, iniciada por Ximénez de Cisneros en Granada hacia 1500, de que los musulmanes se convirtieran al cristianismo y se hicieran bautizar. Los bautismos forzosos de las germanías valencianas, dos décadas más tarde, extendieron esta situación a la totalidad de los dominios de la Corona de España. 
Ante la presión cristiana para que se hicieran bautizar, los musulmanes intentaron defenderse con el sistema de la taqiyya o kitmân (simulación ante la opresión, que ha sido muy bien estudiada por Louis Cardaillac). Era un principio religioso musulmán, según el cual podian abrazar otra creencia en caso de peligro en su vida y bienes, con tal de que se conservaran interiormente fieles al Islam y procuraran cumplir sus preceptos en la medida de lo posible.

Como defensa islámica ante el ataque cristiano que suponían las presiones para que se bautizaran, cedieron aparentemente. Pero exigieron no caer bajo la jurisdicción del tribunal de la Inquisición, que podía urgar en sus creencias y descubrir la treta para conservar intacto, bajo la simulación aparente, su sistema íntimo de creencias y prácticas musulmanas.

Su pretensión resultó inútil. El control religioso inquisitorial se fue imponiendo sobre esos «cristianos nuevos de moros» - que habria que llamar «cristianos falsos»con un rigor y una minuciosidad imprevisibles. Ante este nuevo acoso, los musulmanes moriscos fueron extremando las precauciones.

Dentro del acoso al que sometieron los cristianos a los moriscos, se dieron nuevos pasos cuando se pretendió controlar no sólo sus creencias religiosas, sino también sus costumbres originales, distintas de las de sus compatriotas cristianos españoles en el terreno lingüístico, alimenticio, higiénico, vestimentario, de fiestas, etc., aunque no fueran contra ningún precepto religioso especificamente cristiano.

Como se verá más adelante, algunas autoridades cristianas juzgaban que esas costumbres especificas de los moriscos eran «tentaciones» que contribuian a mantener su solidaridad comunitaria islámica y que habian de suprimirse para ligarles plenamente al cristianismo. No les faltaba razón en el planteamiento, porque los moriscos cuidaban estas señales de identidad como una forma de identificación con el sistema musulmán, que mantenian intacto en sus corazones.

Lo que falló, por parte cristiana, fueron los medios. Los moriscos sintieron esas prohibiciones como un ataque frontal y se rebelaron en Las Alpujarras. Fueron vencidos y todos tuvieron que ceder y adaptarse a los usos cristianos. Perdieron así nuevos signos de identidad, que al fin y al cabo eran secundarios en su sistema, porque conservaban en su corazón y aún en muchos usos sociales más o menos escondidos la adhesión al sistema de creencias islámicas.

Evidentemente, el máximo choque con las autoridades cristianas fue la expulsión definitiva, la emigración definitiva a tierras musulmanas. Suponia abandonar el ideal de recuperación política de al-Andalus para el Islam y conllevaba la durísima prueba de la pérdida de sus bienes y de su tierra para una aleatoria instalación en tierras extrañas.

Aquí también se adaptó la comunidad musulmana en su conjunto, en España y en los países islámicos, a una situación de ataque gravísimo contra su sistema de creencias. La expulsión total de Felipe III fue considerada por algunos teóricos emigrados como una salvación divina, como la salida de Egipto del pueblo judío. Se había salvado lo esencial, la fe, mantenida sustancialmente intacta a través de los siglos, a pesar de los ataques cada vez más peligrosos de las fuerzas del mal, representadas para ellos por los poderes cristianos del Estado, la Iglesia y la Inquisición. 
En resumidas cuentas, las creencias islámicas se mantienen idénticas a lo largo de los siglos de dominación del poder cristiano sobre los musulmanes. Los moriscos no pueden entenderse sin la referencia a los musulmanes y mudéjares precedentes. A pesar de la graduación de la opresión cristiana, ellos supieron encontrar en el Islam los principales teológicos que justificaban su adaptación a circunstancias que consideraban ofensivas para la supervivencia del sistema religioso musulmán.

\section{La evolución de los problemas teológicos cristianos con los musulmanes españoles}

El cristianismo, especialmente el latino occidental, al encontrarse con el fenómeno religioso del Islam, tomó posturas diversas, que han sido muy estudiadas (recientemente por Rafael Benítez) y que aquí sólo se mencionarán en relación con el «problema morisco».

Dentro del desconcierto inicial cristiano ante el surgir del Islam en Oriente Medio (no se sabia si los musulmanes eran una secta cristiana nueva, remodelación de movimientos heterodoxos antiguos), los cristianos acaban por considerar que el Islam es diferente del Cristianismo, aunque reconocen la tolerancia islámica, que permite el libre ejercicio de la religión con tal de que se reconozca la autoridad superior del gobierno musulmán y se paguen los impuestos especiales. Por ejemplo, Juan de Gortz, el monje alemán y embajador ante la corte de Abderrahmán III, en plenoz siglo $X$, escucha de los cristianos cordobeses que con los musulmanes sólo han perdido la independencia política y fiscal, lo cual coincide con las lamentaciones de la crónica mozarábiga y con Eulogio, que se queja de la pérdida de la cultura latina entre los cristianos arabizados de al-Andalus. En este mismo ambiente que encontró San Juan de Gortz durante su estancia en Córdoba, parece que ya no se hablaba de los mártires cristianos del siglo pasado y que no se aplicaban por ello a los musulmanes las categorías teológicas que los cristianos habían aplicado a sus perseguidores paganos, en los primeros siglos de la era.

En cambio se advierte una agresividad antimusulmana en el campo político-moral: los musulmanes serán considerados como inmorales incivilizados y, sobre todo, como usurpadores de los territorios y santuarios cristianos. Cruzadas, reconquistas y otras acciones político-militares forman parte del apoyo tradicional de las iglesias cristianas a las autoridades que les permiten el ejercicio de sus actividades espirituales y les dan las bases materiales para la estructura de la organización eclesiástica. A lo largo de la Edad Media y hasta el siglo XVII, la Iglesia cristiana dará su cobertura teológica para las acciones políticas del poder civil en el "problema morisco».

Además de esta motivación político-religiosa, hay principios teológicos estrictamente espirituales que guían la actuación cristiana contra los musulmanes o al menos contra sus creencias.

El primero es el de la evangelización de los no-cristianos, como lo son los musulmanes. La evangelización nace del precepto divino de predicar a todas las gentes y de la caridad fraterna de los cristianos, que quieren salvar a los «infieles» de la perdición eterna.

La evangelización o cristianización se encuentra con dos obstáculos, una vez alejada la presencia de los paganos, convertidos generalmente al cristianismo, en 
la sociedad europea. Con cada vez más fuerza y agresividad se va a buscar la conversión de los judios y musulmanes, así como de los pecadores y herejes cristianos, evidentemente.

Pero la conversión personal no es fácil. Exige una predicación para conocer las verdades de fe, pero ésta no viene sin la gracia divina y sin la cooperación libre del hombre. Los «convertidores» pueden predicar lo mejor posible y hasta suponer que Dios quiere que todos los hombres se salven en el Cristianismo y da gracia suficiente para que el hombre pueda aceptar los misterios de la fe cristiana, pero siempre quedan incógnitas en el proceso de la conversión, especialmente en los obstáculos que pone el hombre mismo, con su aceptación o rechazo culpable de la fe.

Entre todas estas premisas para la conversión - predicación, gracia divina, inteligibilidad de los misterios, cooperación a la gracia - los convertidores insistirán en la cooperación personal a la gracia, aunque sin dejar de plantearse interrogantes sobre la eficacia de los otros elementos en el caso de la conversión de los musulmanes. Así, judíos y musulmanes, si no se convertían al cristianismo era seguramente por pertinaz oposición a la gracia divina. Debian de ser castigados por ello, hasta que su libertad, al menos movida por la corrección o por interés, aceptara abrazar la fe cristiana. Así se justificaba la coacción en las conversiones, a pesar de las incógnitas de las gracias divinas para la obtención de la fe.

En realidad, el problema teológico de la gracia, tan fundamental en la teología española del siglo XVI-XVII, era un profundo problema político: si la fe y sus derivaciones prácticas dependian de la gracia divina, la autoridad cristiana y sus organismos «cristianizadores», como la Inquisición, no tenían una acción decisiva en el control religioso y moral de los españoles. Gracia divina y acción religiosa coadyuvante se frenaban mutuamente (salvo siempre el poder divino de hacer milagros). El Estado cristiano y la Iglesia, con sus medios coordinados, podían ponerlos todos para preparar la conversión, pero la eficacia de su acción debía depender de la gracia divina. Era un problema espinoso para los gobernantes empeñados en una acción de unificación religiosa y de control moral. Era un problema fundamental para la actividad de los tribunales de la Inquisición.

En resumidas cuentas, había que suponer la gracia divina para poder atribuir la no conversión del judío y del musulmán (o de cualquier pecador) al rechazo consciente y libre, y por tanto punible, ya en esta vida.

Para suponer esta gracia divina o hacerla casi automática, ligada necesariamente a un hecho visible y controlable, la teologia cristiana distinguía dos gracias: gracia ex opere operantis, que dependia de la voluntad del hombre y era por tanto subjetivo e incontrolable en el caso del sujeto pasivo del bautizado adulto al que se requería consentimiento, y gracia ex opere operato, de efecto perfectamente controlable, supuestas unas circunstancias o condiciones preestablecidas, dado el pacto o «Testamento» de Dios con la Iglesia, distribuidora de Su gracia.

Esta doble via de la gracia divina va a jugar un papel muy importante en el uso del sacramento del bautismo, rito de conversión a la fe cristiana, aplicado a judíos y musulmanes.

En efecto, el uso cristiano latino de bautizar a los niños recién nacidos, sin que 
pudieran ejercer su libertad, que era asumida por los padres o padrinos, proporcionaba un ejemplo claro de acción que conllevaba automáticamente la gracia de ser cristiano. Más aún, era irreversible, ya que el sacramento imprimia carácter.

Claro está -y por eso hubo tensiones teológicas, especialmente tras los bautismos forzosos de las germanías valencianas- que para los adultos se requería el consentimiento previo. Pero éste obtenido, aunque fuera con presiones que coartaran la libertad pero no la suprimieran, la gracia podía venir directamente con el acto bautismal y producir el efecto de conversión, efecto permanente por la doctrina teológica - no de fe- del carácter imborrable del sacramento. Si en los adultos se requería la libre aceptación, los teólogos cristianos pensaban que ésta no era incompatible con cierta coacción, ya que si los musulmanes no hubieran querido ser bautizados, hubieran llegado a resistir hasta el martirio. Esta noción de martirio hasta la muerte era especificamente cristiana, ya que la taqiyya, kitmân o simulación islámica no se da sólo ante peligro de muerte, sino simplemente ante cualquier perjuicio grave.

Las objeciones sobre la validez de esos bautismos forzados y hasta la misma creencia popular de que «es agua inútil la que se emplea en bautizar un judio», no parece impidieron que los bautizadores de judíos y moriscos confiaran en la gratia ex opere operato, sobre todo en los niños moriscos, salvados gracias a este remedio de ir al infierno eterno. Los antecedentes de pueblos nórdicos europeos, bautizados en masa en época altomedieval, debía pesar en la mente de Cisneros, de los agermanados y de los demás bautizadores, que consideraban asi el bautismo como algo irreversible. La práctica con los amerindios confirmaba este procedimiento.

Es evidente que ni judíos ni moriscos participaban de esa creencia.

Estas dudas presidían la actuación de los poderes cristianos y especialmente los inquisitoriales: en el caso de los moriscos, ¿se estaba actuando con «malos cristianos»? Porque si no eran cristianos, ni tenían la gracia divina para serlo, la Inquisición no tenía jurisdicción sobre ellos. Y el Estado cristiano tenía que aceptarlos como musulmanes, como lo habia hecho con las comunidades mudéjares, o eliminarlos de la convivencia nacional, que es lo que en definitiva se hizo.

Pero la Inquisición, que los consideraba generalmente como «malos cristianos», se plantearía el problema de cómo hacerles efizcamente «buenos cristianos». Aquí entra el factor de las tentaciones, especialmente las de origen social.

El cristianismo considera esencialmente la salvación como un factor individual, en el que coadjuvan fuerzas sociales del bien, que son sobre todo las ayudas sobrenaturales de la Iglesia y de sus sacramentos. En cambio los peligros para la salvación (tentaciones) pueden provenir del ambiente social no eclesial (el «mundo»), de uno mismo, especialmente del cuerpo débil (la «carne») y del demonio, que azuza por todas partes: es el «mundo, demonio y carne», de los catecismos católicos.

Por eso la Inquisición - y la Iglesia española en general-- se movieron en dos planos para neutralizar las «tentaciones» que podían apartar a los «cristianos nuevos de moros» de su «mundo» tentador por excelencia, el mundo del Islam.

Por una parte, aumentaban las ayudas eclesiales para el bien (sacramentos, predicación, clero,...) y por otra, evitaban las influencias sociales que les ligaran al Islam. Eso justificaba, sobre todo, las medidas de desintegración y aislamiento sociales 
que se aplicó a los moriscos: mezclarlos con cristianos viejos, expulsarlos de las regiones donde se concentraban, arrebatarles a los niños para que se educaran con «Cristianos viejos», etc.

Éstas son pues las etapas o articulaciones de un pensamiento cristiano evidentemente complejo, frente a la constante acción defensiva de los moriscos, fieles al conjunto del sistema de fe islámica.

Los tres poderes cristianos (Estado, Iglesia, Inquisición) actuarán de acuerdo con esos principios en su esfera propia. Los musulmanes se adaptarán, según sus propios principios islámicos, frente a esas actuaciones de los poderes cristianos.

\section{Los moriscos frente a los poderes cristianos}

Frente al Estado cristiano (medieval y moderno), los musulmanes intentaron obtener el estatuto islámico de minoría religiosa protegida, como el que ellos habian otorgado a judíos y cristianos, mediante el sometimiento político y el pago de impuestos especiales. Es el sentido de las cantidades diversas que entregaban a las autoridades cristianas (políticas y señoriales, pero también eclesiásticas) para obtener la conservación de sus tradiciones religiosas vitales. Se someten, mientras la opresión cristiana sea soportable - al igual que habian soportado a sus autoridades musulmanas, a veces igualmente opresivas - y mientras no hubiera esperanza de un triunfo militar musulmán. Esperan con ello mantener lo esencial de su cohesión comunitaria, dentro del sistema religioso que conocen en el Islam, para las otras religiones. Hay datos como para pensar que quizás se hubiera podido lograr la permanencia de este «modus vivendi» mudéjar, estable por ambas partes.

Frente a la Iglesia cristiana, los musulmanes actúan con una oposición radical en el fondo (no quieren por nada del mundo ser cristianos), pero sin choques estridentes, dada la debilidad de la acción evangelizadora de la Iglesia (ignorancia general del clero, incomunicabilidad lingüística, poca mella de las creencias cristianas en la fe islámica, etc.). Además, acostumbrados por la enseñanza coránica al respeto general al cristianismo y a sus ministros (lo que no excluye burlas en temas concretos), los musulmanes se acomodaban fácilmente a la coexistencia con los eclesiásticos, mientras éstos no les opriman en su fe, costumbres y bienes.

Pero toda la agresividad de los moriscos musulmanes se concentra en la Inquisición, que era el organismo cristiano - delegado por el Estado cristiano y por la Iglesia cristiana- encargado de vigilar, controlar y oprimir su fe. El carácter opresivo de la Inquisición se debía, para los moriscos, a que se juntaba el carácter religioso con el represivo. Podían soportar al Estado represivo y a la Iglesia predicadora. Pero no a la Inquisición ${ }^{\star}$.

\footnotetext{
*Este texto fue presentado como ponencia en el Simposio «La Inquisición y los poderes políticos» (Madrid/Alcalá/Sigüenza, 1984), aún inédito. Sus ideas básicas se han presentado también en el capítulo «Principes chrétiens et principes musulmans face au problème morisques; en la obra colectiva dirigida por Louis Cardaillac, Les Morisques et I'Inquisition, París, Publisud, 1990, pp. 37-50.
} 